\title{
Bicarbonate Transport Along the Loop of Henle

\author{
II. Effects of Acid-Base, Dietary, and Neurohumoral Determinants
}

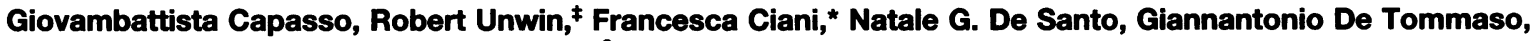 \\ Ferdinando Russo, ${ }^{*}$ and Gerhard Giebisch ${ }^{\mathbf{s}}$ \\ Chair of Nephrology, Faculty of Medicine and *Department of Biological Structures and Functions, 1st. and 2nd. Universities of Naples, \\ Naples, Italy; ${ }^{\ddagger}$ Departments of Nephrology, Medicine and Physiology, University College London Medical School, London, United \\ Kingdom; and ${ }^{8}$ Department of Cellular and Molecular Physiology, Yale University, New Haven, Connecticut 06520
}

\begin{abstract}
The loop of Henle contributes to renal acidification by reabsorbing about $15 \%$ of filtered bicarbonate. To study the effects on loop of Henle bicarbonate transport $\left(\mathrm{JHCO}_{3}\right)$ of acid-base disturbances and of several factors known to modulate sodium transport, these in vivo microperfusion studies were carried out in rats during: (a) acute and chronic metabolic acidosis, (b) acute and chronic (hypokalemic) metabolic alkalosis, (c) a control sodium diet, $(d)$ a high-sodium diet, (e) angiotensin II (AII) intravenous infusion, $(f)$ simultaneously intravenous infusion of both AII and the $\mathrm{AT}_{1}$ receptor antagonist DuP 753, (g) acute ipsilateral mechanicochemical renal denervation. Acute and chronic metabolic acidosis increased $\mathrm{JHCO}_{3}$; acute metabolic alkalosis significantly reduced $\mathrm{JHCO}_{3}$, whereas chronic hypokalemic alkalosis did not alter $\mathrm{JHCO}_{3}$. Bicarbonate transport increased in animals on a high-sodium intake and following AII administration, and the latter was inhibited by the AII $\left(\mathrm{AT}_{1}\right)$ receptor antagonist DuP 753; acute renal denervation lowered bicarbonate transport. These data indicate that bicarbonate reabsorption along the loop of Henle in vivo is closely linked to systemic acid-base status and to several factors known to modulate sodium transport. (J. Clin. Invest. 1994. 94:830-838.) Key words: loop of Henle • high sodium diet • angiotensin II - DuP $753 \cdot$ renal denervation
\end{abstract}

\section{Introduction}

The role of the loop of Henle (LOH) ${ }^{1}$ in acid-base balance has been established by micropuncture studies that showed that a significant fraction of filtered bicarbonate was reabsorbed along

Address correspondence to Gerhard Giebisch, M.D., Department of Cellular \& Molecular Physiology, Yale University School of Medicine, 333 Cedar Street, New Haven, CT 06520.

Received for publication 20 September 1993 and in revised form 8 April 1994.

Part of this study was presented at the 1989 and 1991 Annual Meetings of the American Society of Nephrology and published in abstract form (1990. Kidney Int. 37:534a, and 1991. J. Am. Soc. Nephrol. 2:697a)

1. Abbreviations used in this paper: AII, angiotension II; ANCOVA, analysis of covariance; $\mathrm{LOH}$, loop of Henle; TAL, thick ascending limbs.

J. Clin. Invest.

(c) The American Society for Clinical Investigation, Inc.

0021-9738/94/08/0830/09 \$2.00

Volume 94, August 1994, 830-838 this nephron segment $(1,2)$. Subsequent studies of isolated thick ascending limbs (TAL) from rat kidneys confirmed directly the ability of this tubule segment to reabsorb bicarbonate by a carbonic anhydrase-sensitive mechanism of $\mathrm{Na}^{+}-\mathrm{H}^{+}$exchange (3). Such studies also provided evidence for a possible regulatory role of the TAL in bicarbonate reabsorption by demonstrating a reduction of reabsorptive transport in chloride-depletion alkalosis and stimulation in acidosis $(4,5)$. Perfusion studies of the $\mathrm{LOH}$ in vivo have not only confirmed the contribution of $\mathrm{Na}^{+}-\mathrm{H}^{+}$exchange to bicarbonate absorption, but also have revealed a significant contribution of electrogenic $\mathrm{H}^{+}$secretion to the process of acidification (6).

The assessment of the role of the LOH in modulating bicarbonate transport in vivo by perfusion from late segments of the proximal convoluted tubule is complicated by the fact that this nephron segment is heterogeneous and composed of several subsegments: the S3 segment of the proximal tubule, the thin descending limb, the TAL, and a small portion of early distal tubule. Studies of the $\mathrm{LOH}$ in the rat in vivo indicate that the thin descending limb has a low bicarbonate permeability and is unlikely to play a major role in bicarbonate reabsorption $(7,8)$. In contrast, the $\mathrm{S} 3$ segment of the proximal tubule has been found to reabsorb bicarbonate by a process involving $\mathrm{Na}^{+}-\mathrm{H}^{+}$ exchange (9).

Several mechanisms are known to mediate the complex relationship between sodium balance and $\mathrm{H}^{+}$transport along the nephron. Sodium balance may affect bicarbonate transport directly, through altered sodium delivery to sites of acidification (10), or indirectly, through changes in aldosterone release (11). Changes in sodium intake modulate $\mathrm{Na}^{+}-\mathrm{H}^{+}$exchange in brush border membrane vesicles from rat renal cortex. Similarly, bicarbonate transport is increased in the TAL from animals on a high-sodium diet (5). The release of aldosterone is altered by sodium balance and has been shown to activate $\mathrm{H}^{+}$secretion in distal nephron segments (12). Renin and angiotensin secretion are also affected by changes in sodium balance (13) and angiotensin II (AII) is a potent activator of $\mathrm{Na}^{+}-\mathrm{H}^{+}$transport along the proximal tubule (14). Autonomic nerve traffic to the kidney is also modulated by changes in sodium balance (15), and immunohistochemical and autoradiographic studies demonstrate autonomic innervation of nephron segments, including the TAL (16). Significant effects of renal denervation on proximal and distal tubule sodium bicarbonate reabsorption have been reported $(17,18)$.

The present studies were undertaken to examine the response of the LOH of superficial nephrons to acid-base disturbances and to chronic sodium loading. Since a high dietary sodium intake is associated with suppression of the renin-angiotensin-aldosterone system (13) and of renal nerve activity (19), we have separately examined the effects of AII and acute 
renal denervation on LOH bicarbonate absorption. Our experiments indicate that: $(a)$ this segment plays a significant role in the response to acid-base derangements; $(b)$ changes in bicarbonate transport followed maneuvers that affect sodium transport in the kidney.

\section{Methods}

Preparation of animals. Experiments were done on a total of 69 Sprague-Dawley rats (180-290 g body wt) and eight male Wistar rats $\left(255-275 \mathrm{~g}\right.$ body wt) grouped in cages at $21^{\circ} \mathrm{C}$. The animals received food and drinking water up to the time of study. Rats were anesthetized intraperitoneally with Inactin (Promonta, Germany; $120 \mathrm{mg} \cdot \mathrm{kg}^{-1}$ body wt) and prepared for micropuncture as previously described (6). A Ringer-saline $\left(125 \mathrm{mM} \mathrm{NaCl}+25 \mathrm{mM} \mathrm{NaHCO}{ }_{3}\right)$ solution was infused at $4 \mathrm{ml} \cdot \mathrm{h}^{-1}$ via a syringe pump (Harvard Apparatus, Inc., South Natick, MA) through PE-50 tubing inserted in a jugular vein. Arterial blood pressure was monitored continuously through a carotid artery catheter connected to a Statham pressure transducer. Urine was drained with PE-10 tubing from the left kidney which had been exposed through a flank incision, freed of perirenal fat and immobilized in a lucite chamber with $3 \%$ Agar in $0.9 \%$ saline. Throughout the experiment the kidney was bathed with prewarmed $\left(37^{\circ} \mathrm{C}\right)$ paraffin oil.

Microperfusion. As in previous studies (6) the technique of continuous microperfusion of superficial $\mathrm{LOH}$ in vivo involved the following steps: Placement of a perfusion pipette into the last surface loop of proximal tubule and a castor oil block upstream of the perfusion pipette. Microperfusion was then started at $20 \mathrm{nl} \cdot \mathrm{min}^{-1}$ with a thermally shielded microperfusion pump (Hampel, Frankfurt, Germany) using a perfusion solution containing the following (mM): $\mathrm{NaCl}, 128 ; \mathrm{NaHCO}_{3}$, $13 ; \mathrm{KCl}, 3.8$ (except in $\mathrm{K}^{+}$-depleted rats in which $\mathrm{KCl}$ was 1.8 or 3.8 and $\mathrm{NaCl} 130$ ); $\mathrm{MgCl}_{2}, 1 ; \mathrm{NaH}_{2} \mathrm{PO}_{4}, 0.38 ; \mathrm{Na}_{2} \mathrm{HPO}_{4}, 1.62$. [ $\left.{ }^{14} \mathrm{C}\right]$ Inulin $\left(12.5 \mu \mathrm{Ci} \cdot \mathrm{ml}^{-1}\right.$ ) was added to the perfusion solution to measure fluid transport and FD\&C blue dye to color the perfusate. A collection pipette was inserted at the matching early distal segment that had been identified by injecting a small droplet of oil in the proximal tubule. A castor oil block distal to the collection site prevented contamination by fluid from more distal nephron sites.

In acute acid-base disturbances, AII, and denervation experiments, control and experimental data were obtained from the same animal. Transport data are given per individual $\mathrm{LOH}$, as it has been shown that the variation of the length of this nephron segment is small $(\sim 6-7$ mm) (20).

Experimental groups. Net bicarbonate transport rate $\left(\mathrm{JHCO}_{3}\right)$ and net fluid flux (Jv) were measured in the following conditions: $(a)$ acute metabolic acidosis induced by injecting a bolus of $0.1 \mathrm{~N} \mathrm{HCl}$ i.v. $(1 \%$ body wt) in isotonic saline followed by a continuous infusion of the same solution at $4 \mathrm{ml} \cdot \mathrm{h}^{-1} ;(b)$ chronic metabolic acidosis produced by replacing the drinking water for the animals with $1.5 \mathrm{~g} \% \mathrm{NH}_{4} \mathrm{Cl}$ for 5$8 \mathrm{~d}$; during the microperfusion experiments these animals received an intravenous infusion of an isotonic bicarbonate-free saline solution at 4 $\mathrm{ml} \cdot \mathrm{h}^{-1} ;(c)$ acute metabolic alkalosis caused by initial injection of an intravenous bolus of $0.5 \mathrm{ml} 1 \mathrm{M} \mathrm{NaHCO}$ followed by continuous infusion of isotonic bicarbonate solution $\left(135 \mathrm{mM} \mathrm{NaHCO}{ }_{3}+15 \mathrm{mM}\right.$ $\mathrm{KHCO}_{3}$ ) at $4 \mathrm{ml} \cdot \mathrm{h}^{-1} ;(d)$ chronic hypokalemic metabolic alkalosis generated by placing animals on a potassium deficient diet (No. 170550; Teklad Premier Laboratory Diets, Madison, WI) for at least $3 \mathrm{wk}$; $(e)$ on control sodium intake $\left(\mathrm{NaCl} 5 \mathbf{g} \cdot \mathrm{kg}^{-1}\right) ;(f)$ high-sodium intake (control diet plus $\mathrm{NaCl} 16.4 \mathrm{~g} \cdot \mathrm{l}^{-1}$ drinking solution for $10-14 \mathrm{~d}$ ); $(g)$ on control sodium intake and following intravenous infusion of AII (20 $\left.\mathrm{ng} \cdot \mathrm{kg}^{-1} \cdot \mathrm{min}^{-1}\right)$, each animal serving as its own control; $(h)$ control sodium intake and intravenous AII along with the AII $\mathrm{AT}_{1}$ receptor antagonist DuP $753\left(40 \mu \mathrm{g} \cdot \mathrm{kg}^{-1} \cdot \mathrm{min}^{-1}\right)$; (i) control sodium intake and acute ipsilateral renal denervation performed by mechanical stripping of the adventitia of the left renal artery followed by application of a $10 \%$ phenol in ethanol solution for at least 20 min before sampling.
Separate control experiments were carried out in each of the experimental conditions.

In conditions $e$ and $f$ several perfusate bicarbonate concentrations were used to evaluate the concentration-dependence of $\mathrm{JHCO}_{3}$. This was achieved by replacing chloride with bicarbonate. Thus, in addition to the control perfusate, the following solutions were used: (i) $\mathrm{NaHCO}_{3}$ $25 \mathrm{mM}$ and $\mathrm{NaCl} 116 \mathrm{mM}$; (ii) $\mathrm{NaHCO}_{3} 37 \mathrm{mM}$ and $\mathrm{NaCl} 104 \mathrm{mM}$.

In separate experiments glomerular filtration rate (GFR) was measured during acute and chronic metabolic acidosis and acute metabolic alkalosis. Chronic hypokalemic metabolic alkalosis was not studied because we have reported values of GFR previously $(21,22)$. Experiments were done on animals ( $n=16 ; 254 \pm 8 \mathrm{~g}$ body wt) prepared for micropuncture as described above. All rats were given a priming dose of 20 $\mu \mathrm{Ci}\left[{ }^{3} \mathrm{H}\right]$ inulin in $0.5 \mathrm{ml} 0.9 \%$ saline, followed by a continuous infusion of $\left[^{3} \mathrm{H}\right]$ inulin at $20 \mu \mathrm{Ci} \cdot \mathrm{h}^{-1}$ in the appropriate solution at $4 \mathrm{ml} \cdot \mathrm{h}^{-1}$, as described in the section on microperfusion. Urine collections of $30 \mathrm{~min}$ duration were started after 45 min equilibration. Arterial blood samples were collected from the carotid artery at the beginning and end of each collection period and replaced with small volumes of isotonic saline.

Analytical methods. Tubule fluid total $\mathrm{CO}_{2}$ concentration was measured by microcalorimetry (Picapnotherm; WPI, New Haven, CT). Each sample analysis was bracketed by running standards of known $\mathrm{Na}_{2} \mathrm{CO}_{3}$ concentration. The arterial blood $\mathrm{pH}, \mathrm{pCO}_{2}$, and calculated plasma bicarbonate concentration of each animal were measured with a blood-gas analyzer (model 170; Corning, Medfield, MA). $\left[{ }^{14} \mathrm{C}\right]$ Inulin radioactivity was measured by a liquid scintillation counter (model P2; Searle, Chicago, IL). Plasma potassium concentration was measured by flame photometry (Corning model 480).

Serum aldosterone levels in some experimental groups were estimated by using a commercial radio-immunoassay kit (Coat-A-Count; Diagnostic Products Corporation, CA).

Calculations and statistical analysis. In the microperfusion experiments perfusion rate $\left(V_{\mathrm{p}}, \mathrm{nl} \cdot \mathrm{min}^{-1}\right)$ was estimated in vivo from the rate of fluid collected multiplied by the ratio of inulin concentrations in collectate/perfusate according to the formula: $V_{\mathrm{p}}=\left(I_{\mathrm{c}} / I_{\mathrm{p}}\right) \times\left(V_{\mathrm{c}}\right)$, where $I_{\mathrm{c}}$ and $I_{\mathrm{p}}$ are the collected and perfused inulin counts, respectively, and $V_{\mathrm{c}}$ is the collection rate $(\mathrm{nl} \cdot \mathrm{min})$. Calculated fluid reabsorption $(J \mathrm{v})$ was the difference between perfusion and collection rates and was derived from the equation: $J v=V_{p}-V_{c}$. Net bicarbonate reabsorption $\left(J \mathrm{HCO}_{3}\right)$ was calculated from the amount of bicarbonate delivered in the perfusion pipette minus the amount collected in the collection pipette according to the following formula: $J \mathrm{HCO}_{3}=\left(C_{\mathrm{p}} \times V_{\mathrm{p}}\right)-\left(C_{\mathrm{c}} \times V_{\mathrm{c}}\right)$, where $C_{\mathrm{p}}$ and $C_{\mathrm{c}}$ are the bicarbonate concentrations of the perfused and collected fluids. The perfusion pump was calibrated by timed collections of fluid delivered directly into counting vials for measurements of $\left[{ }^{14} \mathrm{C}\right]$ inulin concentrations. A sample collection was considered acceptable if the calculated perfusion rate $\left(V_{\mathrm{p}}\right)$ was within $15 \%$ of the calibrated microperfusion pump rate.

Glomerular filtration rate (GFR) was calculated by the standard clearance formula. Statistical analysis was first by one-way analysis of variance and covariance (ANOVA and ANCOVA), followed by comparison with the relevant control value by post hoc least significance difference testing. We have shown previously that bicarbonate absorption along the $\mathrm{LOH}$ is load dependent (6), therefore we used bicarbonate load as a covariate in the ANCOVA of $\mathrm{JHCO}_{3}$ to adjust for differences in bicarbonate delivery in each experimental group. All data are expressed as mean \pm SEM.

\section{Results}

\section{Plasma composition and whole kidney function}

Table I summarizes arterial blood composition of the animals studied in control conditions and during acid-base disturbances. No significant changes in hematocrit values were observed, a finding that indicates absence of major changes in extracellular fluid volume. Blood $\mathrm{pH}$ was significantly reduced in acute and chronic acidosis. Acute metabolic alkalosis and chronic hypoka- 
Table I. Arterial Blood Composition and Systemic Acid-Base Values in Each Treatment Group

\begin{tabular}{|c|c|c|c|c|c|c|c|}
\hline Group & $n$ & $\begin{array}{l}\text { Hct } \\
(\%)\end{array}$ & pH & $\underset{(\mathrm{mmHg})}{\mathrm{pCO}_{2}}$ & $\begin{array}{c}{\left[\mathrm{HCO}_{3}^{-}\right]} \\
(\mathrm{mM})\end{array}$ & $\begin{array}{l}\left.\mathrm{P}^{\mathrm{PNa}}{ }^{+}\right] \\
(\mathrm{mM})\end{array}$ & $\begin{array}{l}\mathrm{P}\left[\mathrm{K}^{+}\right] \\
(\mathrm{mM})\end{array}$ \\
\hline Control & 13 & $47 \pm 1$ & $7.359 \pm 0.006$ & $52.0 \pm 1.1$ & $29.7 \pm 0.6$ & $149.3 \pm 1.0$ & $4.43 \pm 0.08$ \\
\hline (a) Acute Metabolic Acidosis & 3 & $49 \pm 2$ & b7.296 \pm 0.017 & ${ }^{\mathrm{a}} 35.0 \pm 2.2$ & ${ }^{\mathrm{a}} 17.1 \pm 0.6$ & $147.0 \pm 1.5$ & $4.39 \pm 0.23$ \\
\hline (b) Chronic Metabolic Acidosis & 5 & $48 \pm 1$ & $7.215 \pm 0.022$ & $51.2 \pm 1.7$ & ${ }^{\mathrm{a}} 20.8 \pm 1.4$ & $148.3 \pm 2.4$ & a $3.82 \pm 0.10$ \\
\hline (c) Acute Metabolic Alkalosis & 4 & $45 \pm 1$ & ${ }^{\mathrm{a}} 7.512 \pm 0.007$ & ${ }^{b} 46.9 \pm 1.9$ & $37.4 \pm 1.0$ & $149.0 \pm 2.7$ & $3.72 \pm 0.08$ \\
\hline (d) CMA (potassium depletion) & 15 & $46 \pm 1$ & a $7.426 \pm 0.006$ & $56.9 \pm 1.9$ & a $37.4 \pm 1.1$ & $151.5 \pm 1.3$ & ${ }^{\mathrm{a}} 2.08 \pm 0.13$ \\
\hline
\end{tabular}

CMA, chronic metabolic alkalosis induced by dietary potassium depletion ( 3 wk). Abbreviations: $\mathrm{Hct}$, hematocrit; $\mathrm{pH}, \mathrm{blood} \mathrm{pH} ; \mathrm{pCO}_{2}$, blood carbon dioxide tension; $\left[\mathrm{HCO}_{3}^{-}\right]$, calculate plasma bicarbonate concentration; $\mathrm{P}\left[\mathrm{Na}^{+}\right]$plasma sodium concentration; $\mathrm{P}\left[\mathrm{K}^{+}\right]$, plasma potassium concentration. Comparison with appropriate Control by least significance difference testing after one-way ANOVA; mean $\pm S E M ; n=$ no. of rats; ${ }^{\mathrm{a}}$ and ${ }^{\mathrm{b}}, P<0.01$ and $<0.05$, respectively.

lemic metabolic alkalosis induced a significant increase in blood $\mathrm{pH}$. As expected plasma bicarbonate levels fell in acidosis conditions and increased significantly during acute and chronic alkalosis. No significant changes were observed in plasma sodium concentration. Plasma potassium concentration was significantly reduced in acute and chronic metabolic alkalosis, while no significant change in plasma potassium concentration was observed in the acidosis that resulted from induction of acute metabolic acidosis and a slight decrease occurred in chronic acidosis.

No physiologically significant changes in hematocrit, $\mathrm{pH}$, $\mathrm{PCO}_{2}$ or bicarbonate concentrations were observed in the different sodium diets, AII, DuP 753, or acutely denervated groups. It should be noted that systemic blood pressure was not significantly affected by the administered dose of AII (control 129 \pm 6 $\mathrm{mmHg}$, AII $123 \pm 6 \mathrm{mmHg}$ ). In group $h$, in which animals received simultaneously AII and DuP 753 , blood pressure declined from $118 \pm 2$ to $104 \pm 2 \mathrm{mmHg}(P<0.01)$.

Acute renal denervation led to a significant increase in urine flow rate from $2.09 \pm 0.47$ to $3.57 \pm 0.72 \mu \mathrm{l} \cdot \mathrm{min}^{-1} \cdot 100 \mathrm{~g}^{-1}(P$ $<0.05)$. The diuresis was associated with enhanced sodium excretion from $0.16 \pm 0.06$ to $0.59 \pm 0.16 \mu \mathrm{mol} \cdot \mathrm{min}^{-1} \cdot 100 \mathrm{~g}^{-1}$ $(P<0.02)$.

The effects of each acid-base manipulation on GFR were as follows: Acute metabolic acidosis in the present setting did not significantly change GFR $(0.73 \pm 0.09$ vs. $0.71 \pm 0.07$ $\mathrm{ml} \cdot \min ^{-1} \cdot 100 \mathrm{~g}^{-1}$, baseline vs. acute acidosis, respectively) or urine flow rate $\left(13.8 \pm 5.6\right.$ vs. $23.8 \pm 4.8 \mu \mathrm{l} \cdot \mathrm{min}^{-1}$, baseline vs. acute acidosis, respectively), whereas GFR fell during chronic metabolic acidosis $\left(0.44 \pm 0.06 \mathrm{ml} \cdot \mathrm{min}^{-1} \cdot 100 \mathrm{~g}^{-1}, P<0.01\right)$. A significant increase in GFR compared with control values was observed in acute metabolic alkalosis (1.10 \pm 0.05 $\left.\mathrm{ml} \cdot \min ^{-1} \cdot 100 \mathrm{~g}^{-1}, P<0.01\right)$.

\section{Bicarbonate and fluid transport along the loop of Henle EFFECT OF ACID-BASE DISTURBANCES}

Table II and Fig. 1 summarize the microperfusion data on LOH bicarbonate and fluid transport in acid-base disturbances.

Acute metabolic acidosis. Acute metabolic acidosis led to a significant increase in bicarbonate and fluid reabsorption, $\mathrm{JHCO}_{3}$ increasing from $133.9 \pm 7.2$ to $190.2 \pm 5.4 \mathrm{pmol} \cdot \mathrm{min}^{-1}$. The sharp increase in $\mathrm{JHCO}_{3}$ was also reflected in the lower bicarbonate concentration in the collected fluid. Jv significantly increased from 7.2 $\pm 0.4 \mathrm{nl} \cdot \mathrm{min}^{-1}$ in control to $9.0 \pm 0.3$ $\mathrm{nl} \cdot \mathrm{min}^{-1}$. It should also be noted that the enhancement of bicar- bonate reabsorption is evident from the significant increase in fractional bicarbonate reabsorption.

Chronic metabolic acidosis. Compared to a control group, the chronically acidotic animals reabsorbed significantly more bicarbonate $\left(193.5 \pm 7.0 \mathrm{pmol} \cdot \mathrm{min}^{-1}\right)$ than the control animals $\left(153.5 \pm 4.3 \mathrm{pmol} \cdot \mathrm{min}^{-1}\right)$.

Acute metabolic alkalosis. The results of experiments in which animals were acutely challenged with a bicarbonate load that led to a significant increase of plasma bicarbonate from $29.7 \pm 0.6$ to $37.4 \pm 1.0 \mathrm{mM}$ indicate that $\mathrm{JHCO}_{3}$ was significantly inhibited from $151.6 \pm 4.2$ to $92.1 \pm 8.3 \mathrm{pmol} \cdot \mathrm{min}^{-1}$. The diminished rate of bicarbonate reabsorption was associated with a sharp increase in bicarbonate concentration in the collected perfusate. Fractional bicarbonate reabsorption declined from 69 to $40 \%$. No significant change in $\mathrm{Jv}$ was observed.

Chronic hypokalemic metabolic alkalosis. Bicarbonate and fluid transport remained unchanged during chronic metabolic alkalosis. To test whether lowering the potassium concentration in the perfusate affected bicarbonate absorption, LOH were perfused with solutions containing either 3.8 or $1.8 \mathrm{mM}$ potassium. Compared with control transport rates, bicarbonate absorption remained unchanged in hypokalemic alkalosis both at high and at low potassium concentrations.

\section{FACTORS AFFECTING RENAL SODIUM HANDLING}

Table III and Fig. 2 summarize the data on LOH bicarbonate and fluid transport under conditions of altered sodium metabolism.

Effects of high-sodium intake. During chronic $\mathrm{NaCl}$ loading bicarbonate and fluid absorption along the $\mathrm{LOH}$ were measured at three concentrations of luminal bicarbonate, ranging from 13 to $37 \mathrm{mM}$. The present experiments confirm previous studies in which significant load-dependence of bicarbonate absorption was observed (6). It is also apparent that bicarbonate transport and fractional reabsorption of bicarbonate were significantly increased in sodium-loaded animals at each bicarbonate load. There was also a significant and parallel increase of fluid absorption.

Effects of AII infusion. The infusion of AII led to a modest, but significant increase of $\mathrm{JHCO}_{3}$ from 133 to $166 \mathrm{pmol} \cdot \mathrm{min}^{-1}$. (It should be noted that in this set of experiments Wistar rats were used. This may account for the lower $\mathrm{JHCO}_{3}$ observed under control conditions. However, these animals served as their own controls.)

The results of perfusion studies in which the effects of combined intravenous infusion of $\mathrm{AII}$ and the $\mathrm{AII}\left(\mathrm{AT}_{1}\right)$ receptor 


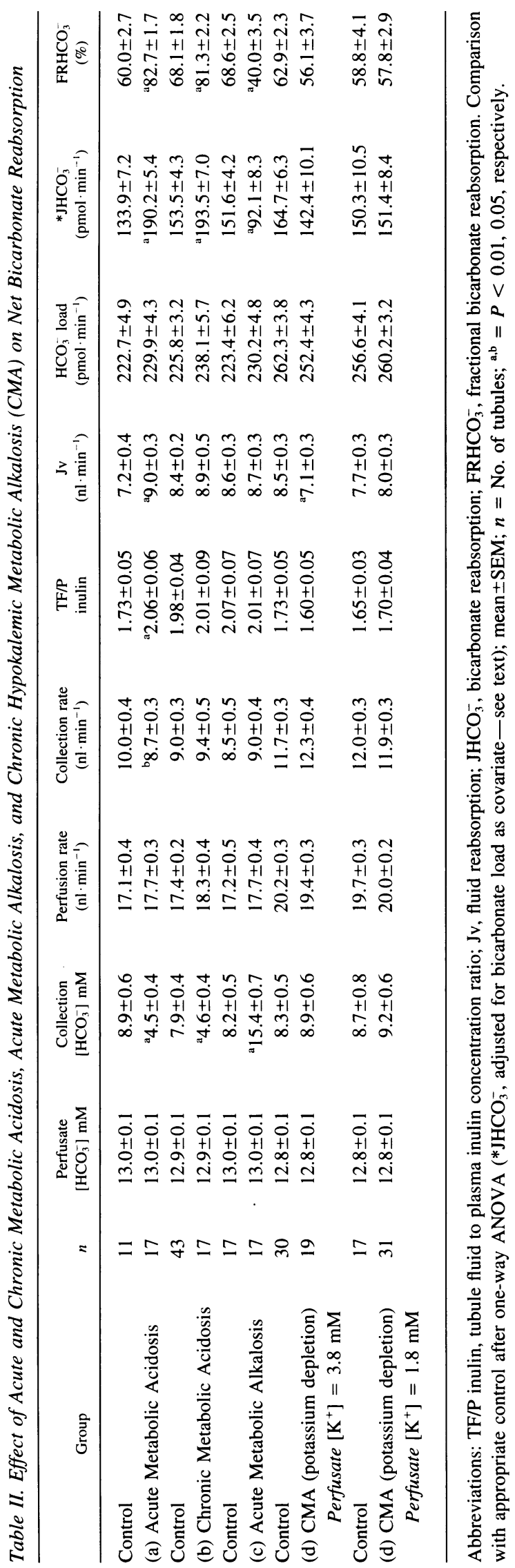

antagonist DuP 753 were investigated indicate that the inhibitor abolished the stimulatory effect of AII on bicarbonate transport. Infusion of AII plus DuP 753 did not induce any significant changes in Jv.

Effects of acute unilateral renal denervation. Acute renal artery denervation induced a fall of $\mathrm{LOH}$ bicarbonate transport from 164 to $134 \mathrm{pmol} \cdot \mathrm{min}^{-1}(P<0.02)$. $\mathrm{Jv}$ was also reduced from 8.8 to $6.1 \mathrm{nl} \cdot \min ^{-1}(P<0.01)$.

\section{Discussion}

The advantages of studying the effects of acid-base disturbances by perfusing Henle's loop in vivo are twofold. First, this approach allows an assessment of loop function in vivo under conditions in which the physiological response to the extracellular environment is preserved. Second, perfusion experiments with controlled solute delivery to the LOH avoid the effects of changes in the filtered load and thus allow study of transport rates at constant luminal delivery of bicarbonate.

As we have discussed before, the microperfused $\mathrm{LOH}$ is an heterogeneous part of the nephron made up of at least four segments, including the pars recta (S3) of the proximal tubule, the thin descending limb of Henle's loop, the TAL, and the initial portion of the distal convoluted tubule. It is the S3 and TAL that are likely to contribute most to the net bicarbonate reabsorption measured in perfusion experiments. Estimates of bicarbonate reabsorption from in vitro rat S3 (9) and of rat medullary TAL (3) show that these two segments combined can account for a rate of bicarbonate reabsorption similar to that observed in the superficial LOH in vivo (6). Since, under normal conditions, the concentration of bicarbonate has reached the limiting transepithelial gradient by the time tubule fluid enters the pars recta, it is likely that the $\mathrm{S} 3$ segment contributes only a small fraction to loop bicarbonate reabsorption. Similarly, the fact that bicarbonate concentration increases along the thin descending limb of Henle's loop $(1,8)$, suggests that only a modest fraction of bicarbonate is lost as tubule fluid enters the TAL. Thus, as postulated by Good (23), the TAL is an important tubule segment reabsorbing bicarbonate during perfusion of the $\mathrm{LOH}$ in vivo.

However, the bicarbonate concentration in the lumen is less than that in the peritubular fluid. Accordingly, a favorable driving force exists for bicarbonate diffusion into the lumen, a process that may modify the overall rate of net absorption of bicarbonate along the loop of Henle.

Effects of acute and chronic metabolic acidosis. At a fixed bicarbonate load, both acute and chronic metabolic acidosis resulted in a significant increase of bicarbonate reabsorption along the $\mathrm{LOH}$. These data confirm freeflow observations in which the comparison of late proximal and early distal bicarbonate deliveries in chronic metabolic acidosis also showed an increase in fractional reabsorption (2). A micropuncture study in which titratable acid excretion was compared between late proximal tubule, the bend of Henle's loop, and the distal tubule showed that net acid excretion was increased along the nephron during chronic metabolic acidosis (7). Freeflow micropuncture and stationary microperfusion studies in the rat proximal tubule have also demonstrated an increased transport capacity for $\mathrm{H}^{+}$ in metabolic acidosis $(24,25)$. Thus, our experiments extend the nephron sites of increased bicarbonate reabsorption during metabolic acidosis to include the LOH. Our findings are also consistent with the observation of Good (5) who showed, in a 


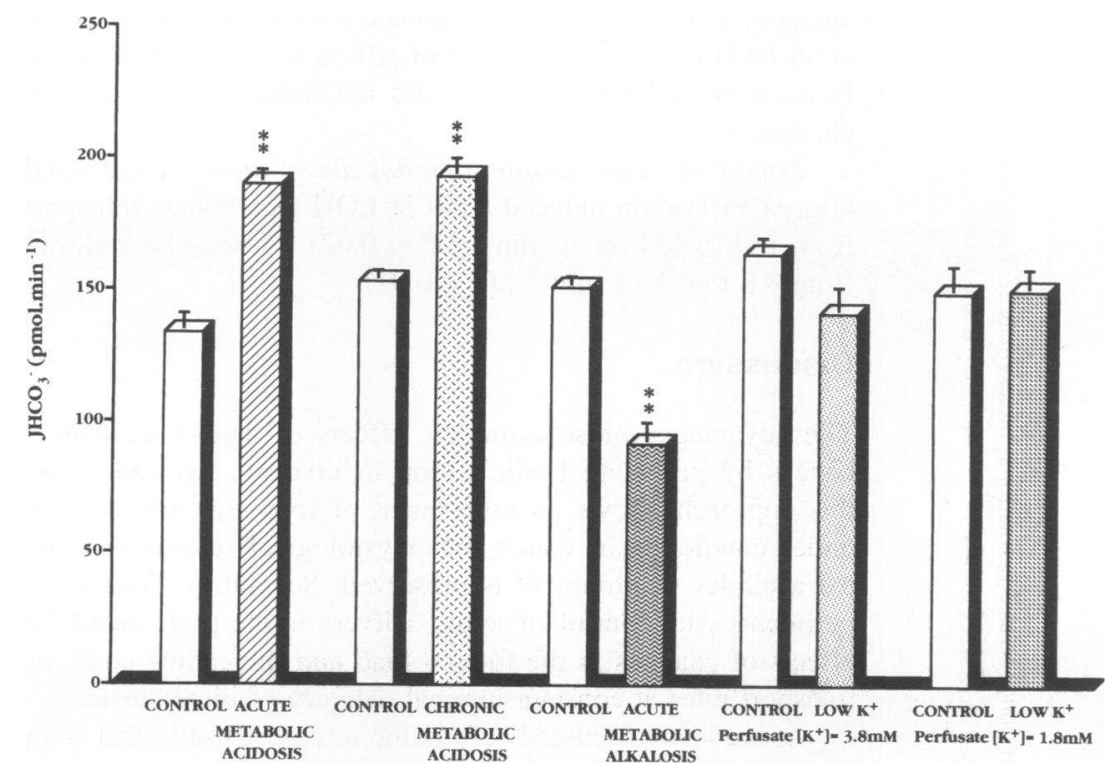

Figure 1. The effect of acute and chronic metabolic acidosis, acute and chronic (secondary to dietary potassium depletion) metabolic alkalosis on bicarbonate $\left(\mathrm{JHCO}_{3}\right)$ reabsorption along the loop of Henle. ${ }^{* *} P<0.01$ vs. Control; mean \pm SEM. similar model of chronic metabolic acidosis, significantly enhanced bicarbonate reabsorption in isolated medullary TAL.

In previous experiments we have observed that two distinct processes contribute to bicarbonate absorption along the $\mathrm{LOH}$ (6). The largest fraction of bicarbonate transport is mediated by $\mathrm{Na}^{+}-\mathrm{H}^{+}$exchange and a smaller component occurs through $\mathrm{H}^{+}$ secretion driven by the activity of $\mathrm{H}^{+}$-ATPase. Studies of several tubule segments suggest that both of these mechanisms can adapt to, and are regulated by, changes in the systemic acidbase status. Intracellular $\mathrm{pH}$ recordings (26) in proximal tu- bules, measurements of $\mathrm{Na}^{+}-\mathrm{H}^{+}$exchange and bicarbonate extrusion in brush border and basolateral membrane vesicles (27, 28 ), as well as determination of $\mathrm{H}^{+}$-ATPase activity $\left(\mathrm{H}^{+}\right.$-ATPase) in different nephron segments $(29,30)$, are consistent with stimulation of $\mathrm{H}^{+}$secretion by acidosis. Recently, it has also been shown that expression of mRNA for the $\mathrm{Na}^{+}-\mathrm{H}^{+}$ antiporter in proximal tubule cells is almost doubled in response to metabolic acidosis (31). It is reasonable to assume that the same mechanisms that operate to increase $\mathrm{Na}^{+}-\mathrm{H}^{+}$exchange and $\mathrm{H}^{+}$-ATPase activity in the proximal and terminal nephron

Table III. Net Bicarbonate Reabsorption in Control Rats (C), in Rats at High-sodium Intake and with Different Perfusate Bicarbonate Concentrations

\begin{tabular}{|c|c|c|c|c|c|c|c|c|c|c|}
\hline Group & $n$ & $\begin{array}{c}\text { Perfusate } \\
{\left[\mathrm{HCO}_{3}^{-}\right] \mathrm{mM}}\end{array}$ & $\begin{array}{c}\text { Collection } \\
{\left[\mathrm{HCO}_{3}^{-}\right] \mathrm{mM}}\end{array}$ & $\begin{array}{l}\text { Perfusion rate } \\
\left(\mathrm{nl} \cdot \mathrm{min}^{-1}\right)\end{array}$ & $\begin{array}{l}\text { Collection rate } \\
\left(\mathrm{nl} \cdot \mathrm{min}^{-1}\right)\end{array}$ & $\begin{array}{l}\text { TF/P } \\
\text { inulin }\end{array}$ & $\begin{array}{c}\mathrm{Jv} \\
\left(\mathrm{nl} \cdot \mathrm{min}^{-1}\right)\end{array}$ & $\begin{array}{c}\mathrm{HCO}_{3}^{-} \text {load } \\
\left(\mathrm{pmol} \cdot \mathrm{min}^{-1}\right)\end{array}$ & $\begin{array}{c}{ }^{*} \mathrm{JHCO}_{3}^{-} \\
\left(\mathrm{pmol} \cdot \mathrm{min}^{-1}\right)\end{array}$ & $\begin{array}{c}\mathrm{FRHCO}_{3}^{-} \\
(\%)\end{array}$ \\
\hline \multicolumn{11}{|l|}{ (e) } \\
\hline $\mathrm{Cl}$ & 73 & $12.6 \pm 0.1$ & $8.1 \pm 0.3$ & $18.5 \pm 0.2$ & $10.1 \pm 0.2$ & $1.88 \pm 0.04$ & $8.4 \pm 0.2$ & $240.8 \pm 3.2$ & $158.1 \pm 3.7$ & $66.0 \pm 1.4$ \\
\hline $\mathrm{C} 2$ & 13 & $24.2 \pm 0.2$ & $19.1 \pm 0.7$ & $19.2 \pm 0.4$ & $13.4 \pm 0.5$ & $1.46 \pm 0.05$ & $5.8 \pm 0.5$ & $464.9 \pm 10.1$ & $208.3 \pm 14.0$ & $44.8 \pm 2.9$ \\
\hline $\mathrm{C} 3$ & 9 & $38.0 \pm 0.0$ & $36.2 \pm 0.9$ & $16.9 \pm 0.5$ & $10.3 \pm 0.3$ & $1.66 \pm 0.04$ & $6.7 \pm 0.4$ & $643.8 \pm 19.9$ & $271.7 \pm 20.9$ & $42.0 \pm 2.5$ \\
\hline \multicolumn{11}{|l|}{ (f) } \\
\hline HiNal & 15 & $12.8 \pm 0.2$ & $7.0 \pm 0.5$ & $19.4 \pm 0.5$ & $9.0 \pm 0.4$ & ${ }^{\mathrm{a}} 2.20 \pm 0.08$ & ${ }^{\mathrm{a}} 10.4 \pm 0.4$ & $251.9 \pm 6.4$ & ${ }^{\mathrm{a}} 186.4 \pm 5.7$ & b74.5 \pm 2.5 \\
\hline $\mathrm{HiNa} 2$ & 9 & $25.8 \pm 0.9$ & ${ }^{b} 15.7 \pm 1.3$ & ${ }^{b} 17.6 \pm 0.6$ & a $9.5 \pm 0.6$ & ${ }^{\mathrm{a}} 1.84 \pm 0.06$ & ${ }^{\mathrm{a}} 7.8 \pm 0.3$ & $456.3 \pm 28.1$ & ${ }^{\mathrm{a}} 306.3 \pm 25.2$ & ${ }^{a} 66.8 \pm 3.1$ \\
\hline $\mathrm{HiNa} 3$ & 12 & $35.9 \pm 0.5$ & aa $29.1 \pm 1.9$ & ${ }^{\mathrm{a}} 20.1 \pm 0.5$ & $11.5 \pm 0.6$ & $1.79 \pm 0.08$ & ${ }^{\mathrm{a}} 8.6 \pm 0.5$ & b722.0 \pm 19.5 & ${ }^{\mathrm{a}} 378.0 \pm 23.0$ & $51.8 \pm 4.3$ \\
\hline \multicolumn{11}{|c|}{ 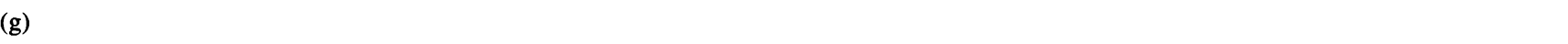 } \\
\hline Control & 15 & $13.2 \pm 0.1$ & $11.0 \pm 0.5$ & $20.6 \pm 0.6$ & $12.5 \pm 0.6$ & $1.70 \pm 0.08$ & $8.2 \pm 0.6$ & $269.8 \pm 7.1$ & $132.8 \pm 9.5$ & $49.2 \pm 3.2$ \\
\hline AII & 15 & $13.2 \pm 0.1$ & a $8.1 \pm 0.7$ & $21.1 \pm 0.5$ & $13.7 \pm 0.7$ & $1.60 \pm 0.09$ & $7.4 \pm 0.7$ & $284.0 \pm 8.8$ & ${ }^{b} 166.5 \pm 12.7$ & ' $59.9 \pm 4.3$ \\
\hline \multicolumn{11}{|l|}{ (h) } \\
\hline Control & 20 & $12.5 \pm 0.0$ & $5.8 \pm 0.7$ & $18.7 \pm 0.3$ & $10.6 \pm 0.5$ & $1.82 \pm 0.07$ & $8.1 \pm 0.4$ & $233.2 \pm 3.7$ & $168.8 \pm 7.6$ & $72.9 \pm 3.5$ \\
\hline $\mathrm{AII}+\mathrm{DuP}$ & 23 & $12.5 \pm 0.0$ & $5.2 \pm 0.6$ & $17.7 \pm 0.4$ & $10.5 \pm 0.5$ & $1.76 \pm 0.07$ & $7.3 \pm 0.4$ & $221.8 \pm 5.0$ & $163.9 \pm 9.2$ & $74.3 \pm 3.9$ \\
\hline \multicolumn{11}{|l|}{ (i) } \\
\hline Control & 27 & $12.4 \pm 0.2$ & $7.1 \pm 0.6$ & $19.6 \pm 0.4$ & $10.7 \pm 0.5$ & $1.90 \pm 0.08$ & $8.8 \pm 0.4$ & $242.1 \pm 4.6$ & $164.4 \pm 7.2$ & $68.5 \pm 3.0$ \\
\hline AURD & 31 & $12.4 \pm 0.2$ & $7.7 \pm 0.6$ & $19.1 \pm 0.3$ & ${ }^{\mathrm{a}} 13.3 \pm 0.7$ & ${ }^{\mathrm{a}} 1.53 \pm 0.06$ & ${ }^{\mathrm{a}} 6.1 \pm 0.5$ & $237.8 \pm 4.3$ & ${ }^{b} 134.5 \pm 9.0$ & b $57.5 \pm 3.8$ \\
\hline
\end{tabular}

Effects on $\mathrm{JHCO}_{3}^{-}$of Angiotensin II (AII, $20 \mathrm{ng} \cdot \mathrm{kg}^{-1} \cdot \mathrm{min}$ ) alone (group g), AII combined with the nonpeptide antagonist DuP 753 (Dup, 40 $\mu \mathrm{g} \cdot \mathrm{kg}^{-1} \cdot \mathrm{min}^{-1}$ ) (group h) and acute unilateral renal denervation (AURD, group i). Abbreviations: TF/P inulin, tubule fluid to plasma inulin concentration ratio; Jv, fluid reabsorption; $\mathrm{JHCO}_{3}{ }^{-}$, net bicarbonate reabsorption; $\mathrm{FRHCO}_{3}{ }^{-}$, fractional bicarbonate reabsorption. Comparison with appropriate Control after one-way ANOVA, mean \pm SEM; $n=$ No. of tubules; ${ }^{\text {a.b }}=P<0.01,0.05$, respectively. 


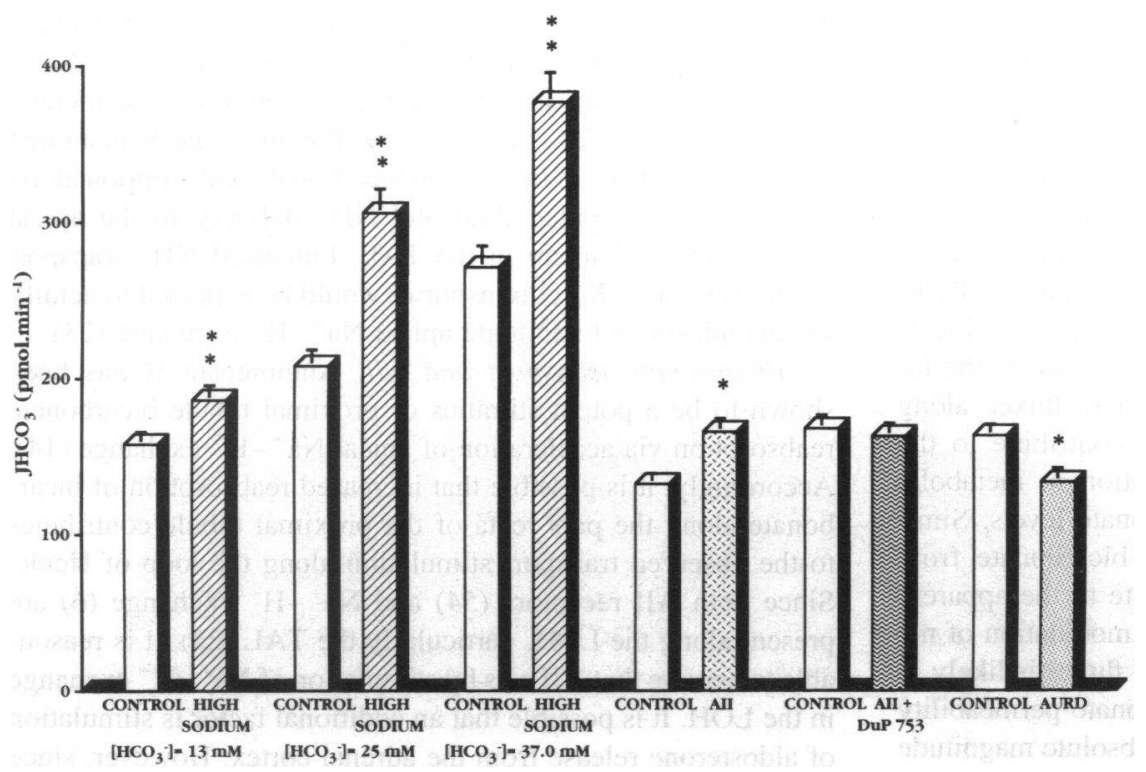

Figure 2. Effect on LOH bicarbonate reabsorption $\left(\mathrm{JHCO}_{3}\right)$ of: (1) increasing perfusate bicarbonate concentration in animals on control and high-sodium intake; (2) i.v. AII infusion (20 $\mathrm{ng} \cdot \mathrm{kg}^{-1} \cdot \mathrm{min}^{-1}$ ); (3) combined i.v. infusion of AII $\left(20 \mathrm{ng} \cdot \mathrm{kg}^{-1} \cdot \mathrm{min}^{-1}\right)$ and its antagonist DuP $753\left(40 \mu \mathrm{g} \cdot \mathrm{kg}^{-1} \cdot \mathrm{min}^{-1}\right)$; (4) acute unilateral renal denervation (AURD); $* P<0.05, * * P$ $<0.01$; mean \pm SEM segments, are also responsible for the significant increase in net acidification and bicarbonate reabsorption that we observed.

It is likely that several hormones participate in stimulating $\mathrm{H}^{+}$secretion in metabolic acidosis. Of particular importance are both gluco- and mineralocorticoids which have been reported to increase in metabolic acidosis (32-34). Glucocorticoids have been shown to activate $\mathrm{Na}^{+}-\mathrm{H}^{+}$exchange in proximal brush border membrane vesicles (27) and their presence is necessary for $\mathrm{Na}^{+}-\mathrm{H}^{+}$antiport stimulation in brush border vesicles from acidotic rats. It is probable that high glucocorticoid levels contribute to the increase in bicarbonate reabsorption in our perfusion studies. We have shown in another study that glucocorticoids and aldosterone stimulate bicarbonate reabsorption along the $\mathrm{LOH}$ in vivo (35). Studies in amphibian early distal tubules, a nephron segment that shares many properties with the TAL, confirm that aldosterone stimulates $\mathrm{Na}^{+}-\mathrm{H}^{+}$exchange (36). The potential role of mineralocorticoid levels was confirmed by significant changes in serum aldosterone levels in our studies. Compared to control values $\left(175 \pm 144 \mathrm{pg} \cdot \mathrm{ml}^{-1}, n=5\right)$, acute and chronic acidosis both increased aldosterone levels (acute acidosis, $421 \pm 53 \mathrm{pg} \cdot \mathrm{ml}^{-1}, n=3$; chronic acidosis, $1,031 \pm 118$ $\mathrm{pg} \cdot \mathrm{ml}^{-1}, n=3$ ).

It should be noted that enhancement of fluid reabsorption was observed in acute, but not in chronic metabolic acidosis. The present experiments do not define the mechanism(s) that may modulate fluid transport in the different segments of the LOH.

Effects of acute metabolic alkalosis. Induction of acute metabolic alkalosis was associated with a significant decline in bicarbonate reabsorption when the increased bicarbonate delivery that normally occurs in this acid-base setting was prevented. The behavior of the bicarbonate transport system in the LOH resembles that in the proximal tubule, where there is a significant fall in bicarbonate transport with elevation of peritubular bicarbonate when changes in luminal bicarbonate delivery are precluded (37). Two factors are likely to mediate the reduction of net bicarbonate transport. First, it is conceivable that the increase in peritubular bicarbonate concentration impedes the exit of bicarbonate, especially electrogenic $\mathrm{Na}^{+}-\mathrm{HCO}_{3}^{-}$cotrans- port, across the basolateral membrane. This mechanism has been invoked to account for inhibition of bicarbonate reabsorption in the proximal tubule (38) and may also account for our similar observations in the $\mathrm{LOH}$, since sodium-coupled bicarbonate transport has been identified in the TAL (39). A second mechanism likely to contribute to diminished bicarbonate reabsorption in acute alkalosis may be the increase in cell $\mathrm{pH}$ and a reduction in apical $\mathrm{Na}^{+}-\mathrm{H}^{+}$exchange.

It is also of interest that Khadouri et al. (29) have reported that in the rat, short-term sodium bicarbonate-induced metabolic alkalosis decreased membrane-bound NEM-sensitive $\mathrm{H}^{+}$-ATPase activity in the medullary TAL. It is likely, but not proven, that a similar acute change in enzyme activity may have contributed to the fall in bicarbonate reabsorption observed in the present study. The observation of Bastani et al. (40) may also be relevant, because these authors demonstrated that cytoplasmic $\mathrm{H}^{+}$-ATPase immunostaining increased in the medulla of alkali-loaded rats at a time when plasma membrane staining disappeared. Freeflow micropuncture studies in volume-expanded animals with acute chloride-depletion alkalosis are in agreement with the present findings by demonstrating a significant fall in LOH fractional bicarbonate reabsorption (41).

Effects of chronic hypokalemic alkalosis. The lack of effect on bicarbonate reabsorption in the hypokalemic rats of the present study may have various explanations. Factors likely to stimulate bicarbonate reabsorption that have been defined in the proximal tubule could involve the following: $(i)$ stimulation of $\mathrm{Na}^{+}-\mathrm{H}^{+}$exchange, secondary to the intracellular acidosis that has been reported in hypokalemia $(42,43)$ and stimulation of an $\mathrm{H}^{+}$-sensitive modifier site (44); (ii) activation of basolateral $\mathrm{Na}^{+}-\mathrm{HCO}_{3}$ cotransport (45); (iii) hyperpolarization of the basolateral membrane with an increase in the driving force for bicarbonate exit (46). While none of these factors have been identified in any the segments of the $\mathrm{LOH}$, it is probable that they are operative in hypokalemia.

The mechanisms that stimulate bicarbonate reabsorption are probably balanced in vivo by inhibition of bicarbonate transport, most likely by enhanced backflux of bicarbonate from blood to lumen along a steeper concentration gradient. Elevated bicar- 
bonate concentration in the peritubular fluid has been shown to suppress bicarbonate reabsorption in the proximal tubule (47).

The role of bicarbonate back-diffusion. In our discussion of the transport mechanisms that contribute to the observed changes in net absorption of bicarbonate in different acid base conditions, we have placed emphasis on modulation of the transcellular pathway for hydrogen and bicarbonate fluxes. However, alterations in net transport rates could also involve passive backdiffusion, largely through paracellular pathways, along bicarbonate concentrations gradient from peritubular fluid to the lumen. Accordingly, reduced passive bicarbonate fluxes along diminished electrochemical gradients could contribute to the apparent increase in net bicarbonate absorption in metabolic acidosis, a condition of lower blood bicarbonate levels. Similarly, in the alkalotic groups, diffusion of bicarbonate from blood to lumen would increase and contribute to the apparent inhibition of net bicarbonate transport. Such modulation of net bicarbonate absorption by changes in passive fluxes is likely in view of the evidence of a significant bicarbonate permeability of the loop of Henle (48-51). However, the absolute magnitude of such passive bicarbonate fluxes is difficult to assess in view of uncertainties of the profile of the electrochemical gradient of bicarbonate along the loop of Henle in the various experimental conditions.

These considerations, and the large body of evidence that changes in ambient bicarbonate and $\mathrm{pH}$ affect cell transport mechanisms of bicarbonate in the thick ascending limb, make it likely that changes in both active and passive bicarbonate fluxes contribute to altered bicarbonate handling by the loop of Henle in acid-base derangements.

Bicarbonate transport and high-sodium intake. One of the main findings of this study was that bicarbonate transport along the LOH increased in animals on a high-sodium intake. These results are consistent with the recent observation that a highsodium intake leads to an increase of bicarbonate absorption in isolated medullary TAL (5). It is unlikely that this increased transport is related to altered levels of aldosterone or AII, hormones which increase bicarbonate reabsorption, because they are suppressed on a high-sodium intake (13). It is also unlikely that the increased reabsorption of bicarbonate in animals on a high-sodium diet is related to changes in sympathetic nerve activity in the kidney. Measurements of efferent nerve activity in different states of sodium balance have shown a decrease, not an increase, during high-sodium intake (19).

To explain the marked increase of bicarbonate transport along the LOH during high-sodium intake, Good (5) has suggested that prolonged and enhanced delivery of sodium, bicarbonate and fluid to the loop, particularly the TAL, may be responsible for increased $\mathrm{Na}^{+}-\mathrm{H}^{+}$exchange. It was hypothesized that increased end-proximal delivery of sodium and bicarbonate to the loop was the result of reduced fluid and bicarbonate reabsorption in the proximal tubule. Consistent with sustained activation of sodium absorption along the loop is hypertrophy of tubule cells following sodium loading. A relevant example are the results of studies by Stanton and Kaissling (52), who chronically increased the delivery of a sodium-rich fluid to initial collecting ducts by chronic furosemide administration. Taking care to prevent fluctuations in mineralocorticoid levels, they observed a sharp increase of sodium absorption that was associated with cell hypertrophy, in particular with amplification of the basolateral cell membranes.

Also consistent with increased activity of the cells of the
TAL following chronic sodium-loading is their high ATPase activity (53). It is possible that such enhanced basolateral $\mathrm{Na}^{+}-$ $\mathrm{K}^{+}$-ATPase may lower cell sodium concentration and thereby accelerate apical $\mathrm{Na}^{+}-\mathrm{H}^{+}$exchange. Finally, a mechanism that also could mediate an increase in bicarbonate reabsorption along the loop is augmented fluid and $\mathrm{NH}_{4}^{+}$delivery to the apical cotransport mechanism in the TAL. Enhanced $\mathrm{NH}_{4}^{+}$transport by the $\mathrm{Na}^{+}-2 \mathrm{Cl}^{-}-\mathrm{K}^{+}$cotransporter would be expected to acidify the cytoplasm and stimulate apical $\mathrm{Na}^{+}-\mathrm{H}^{+}$exchange (23).

Bicarbonate transport and AII. Angiotensin II has been shown to be a potent stimulus of proximal tubule bicarbonate reabsorption via acceleration of apical $\mathrm{Na}^{+}-\mathrm{H}^{+}$exchange (14). Accordingly, it is possible that increased reabsorption of bicarbonate along the pars recta of the proximal tubule contributes to the observed transport stimulation along the loop of Henle. Since both AII receptors (54) and $\mathrm{Na}^{+}-\mathrm{H}^{+}$exchange (6) are present along the $\mathrm{LOH}$, particularly the TAL (23), it is reasonable to assume that $\mathrm{AII}$ acts by stimulation of $\mathrm{Na}^{+}-\mathrm{H}^{+}$exchange in the LOH. It is possible that an additional factor is stimulation of aldosterone release from the adrenal cortex. However, since relatively high levels of aldosterone are needed to stimulate bicarbonate reabsorption in the $\mathrm{LOH}$, this makes it unlikely that this mechanism plays a major role (35).

AII has also been shown to increase sympathetic nerve activity (55). Since we have demonstrated that sympathetic denervation blocks a fraction of bicarbonate reabsorption in the loop (see below), it is possible that AII-induced changes in sympathetic nerve activity may contribute to AII-enhanced bicarbonate absorption along the LOH. It is noteworthy, however, that Liu and Cogan (14) have shown, in the proximal tubule, that stimulation of bicarbonate reabsorption by AII is not dependent on renal nerve activity.

Studies of the effect of AII on bicarbonate transport have demonstrated that the stimulation by AII in the proximal tubule diminished from the $S 1$ segment on $(14,56)$. It is likely that this heterogeneity of the AII response is related to the decline of receptor density, because fewer receptors are present in the pars recta of the proximal tubule and the TAL than the S1 and S2 segments $(54,57,58)$. To confirm that the action of AII depends on direct stimulation of AII receptors we showed that the $\mathrm{AT}_{1}$ nonpeptide antagonist DuP 753 prevented the stimulating effect of AII.

Studies on the cellular mechanism of action of AII in the proximal tubule demonstrate activation of at least two acidbase transporters, including apical $\mathrm{Na}^{+}-\mathrm{H}^{+}$antiporter activity and basolateral electrogenic $\mathrm{Na}^{+}-\mathrm{HCO}_{3}$ cotransport (59). Since both of these transporters have been identified in the TAL (6) it is reasonable to assume that AII stimulates bicarbonate reabsorption by similar mechanisms to those present in the proximal tubule.

Bicarbonate transport and renal denervation. It has been shown that renal denervation inhibits fluid, sodium, and bicarbonate transport in proximal and distal tubules $(17,18)$. Our data extend these observations to the $\mathrm{LOH}$ by demonstrating that acute renal denervation significantly depresses bicarbonate and fluid absorption along the loop. Recently, Bencsath et al. (60) have reported that renal denervation inhibits sodium, potassium, and fluid reabsorption in the TAL, and DiBona and Sawin (61) found that low frequency $(<1 \mathrm{~Hz})$ renal nerve stimulation increased sodium and chloride reabsorption in the LOH.

It is likely that renal denervation acts predominantly by 
activating apical $\mathrm{Na}^{+}-\mathrm{H}^{+}$exchange in the cells of the TAL. Alpha ${ }_{2}$-catecholamines stimulate $\mathrm{Na}^{+}-\mathrm{H}^{+}$antiport activity in the proximal tubule (62). If a similar mechanism is active in the apical membrane of the cells of the TAL, withdrawal of catecholamine-induced stimulation of $\mathrm{Na}^{+}-\mathrm{H}^{+}$exchange by denervation would be expected to diminish net bicarbonate absorption.

Conclusion. Perfusion of the loop of Henle with solutions of a composition approximating that of late proximal tubule fluid has shown that bicarbonate transport is modified in several acid-base disturbances. Net bicarbonate transport was significantly increased in acute and chronic metabolic acidosis and depressed in metabolic alkalosis. No change in bicarbonate transport was found in alkalosis induced by a low potassium diet. Bicarbonate reabsorption was increased by chronic sodium loading and by AII and impaired by renal denervation.

\section{Acknowledgments}

We are grateful to Hanneke Klein-Robbenhaar and Shirley Taylor for expert technical assistance. We thank Dr. R. W. Berliner for helpful comments on the manuscript.

The work was supported by National Institutes of Health grant DK 17433 to G. Giebisch, by CNR grant 89.02468 .04 to G. Capasso and by a Wellcome Trust grant to R. Unwin. G. Capasso and R. Unwin also thank the British Council and Italian Research Council and NATO for collaborative support. G. Capasso also thanks the Society of ItalianAmerican Nephrologists for financial support. DuP 753 was a gift from DuPont Pharmaceuticals.

\section{References}

1. Gottschalk, C. W., W. E. Lassiter, and M. Mylle. 1960. Localization of urine acidification in the mammalian kidney. Am. J. Physiol. 198:581-585.

2. Malnic, G., M. De Mello Aires, and G. Giebisch. 1972. Micropuncture study of renal tubular hydrogen ion transport in the rat. Am. J. Physiol. 222:147158.

3. Good, D. W. 1985. Sodium-dependent bicarbonate absorption by cortical thick ascending limb of rat kidney. Am. J. Physiol. 248:F821-F829.

4. Good, D. W. 1990 . Bicarbonate absorption by the thick ascending limb of Henle's loop. Semin. Nephrol. 10:132-138.

5. Good, D. W. 1990. Adaptation of HCO3- and NH4+ in rat MTAL: effects of chronic metabolic acidosis and Na+ intake. Am. J. Physiol. 258:F1345-F1353.

6. Capasso, G., R. Unwin, S. Agulian, and G. Giebisch. 1991. Bicarbonate transport along the loop of Henle. I. Microperfusion studies of load and inhibitor sensitivity. J. Clin. Invest. 88:430-437.

7. Buerkert, J., D. Martin, and D. Trigg. 1983. Segmental analysis of the renal tubule in buffer production and net acid formation. Am. J. Physiol. 244:F442F454.

8. DuBose, T. D., M. S. Lucci, R. J.HHogg, L. R. Pucacco, J. P. Kokko, and N. W. Carter. 1983. Comparison of acidification parameters in superficial and deep nephrons of the rat. Am. J. Physiol. 244:F497-F503.

9. Garvin, J. L., and M. A. Knepper. 1987. Bicarbonate and ammonia transport in isolated perfused rat proximal straight tubules. Am. J. Physiol. 253:F277-F281.

10. Moe, O. W., A. Tejedor, M. Levi, D. W. Seldin, P. A. Preisig, and R. J. Alpern. 1991. Dietary $\mathrm{NaCl}$ Modulates $\mathrm{Na}+-\mathrm{H}+$ Antiporter Activity in Renal Cortical Apical Membrane Vesicles. Am. J. Physiol. 260:F130-F137.

11. Sealey, J. E., F. R. Buhler, J. H. Laragh, E. L. Manning, and H. R. Brunner 1972. Aldosterone excretion. Physiological variations in man measured by radioimmunoassay or double-isotope dilution. Circ. Res. 31:367-378.

12. Weigt, M., P. Dietl, S. Silbernagl, and H. Oberleithner. 1987. Activation of luminal $\mathrm{Na}+/ \mathrm{H}+$ exchange in distal nephron of frog kidney. An early response to aldosterone. Pflügers Arch. Eur. J. Physiol. 408:609-614.

13. Brown, J. J., D. L. Davies, A. F. Lever, and J. I. S. Robertson. 1964. Influence of sodium deprivation and loading on the plasma renin in man. $J$. Physiol. (Camb.) 173:408-419.

14. Liu, F.-Y., and M. G. Cogan. 1988. Angiotensin II stimulation of hydrogen ion secretion in the rat early proximal tubule. J. Clin. Invest. 82:601-607.

15. DiBona, G. F., and L. L. Sawin. 1983. Renal nerves in renal adaptation to dietary sodium restriction. Am. J. Physiol. 245:F322-F327.

16. Barajas, L., L. Liu, and K. Powers. 1992. Anatomy of the renal innervation: intrarenal aspects and ganglia of origin. Can. J. Physiol. Pharmacol. 70:735749.

17. Cogan, M. G. 1986. Neurogenic regulation of proximal bicarbonate and chloride reabsorption. Am. J. Physiol. 250:F22-F26.

18. Wang, T., and Y. L. Chan. 1989. Neural control of distal tubular bicarbonate and fluid transport. Am. J. Physiol. 257:F72-F76.

19. DiBona, G. F., and L. L. Sawin. 1985. Renal nerve activity in conscious rats during volume expansion and depletion. Am. J. Physiol. 248:F15-F23.

20. Wahl, M., and J. Schnermann. 1969. Microdissection of the length of different tubular segments of rat superficial nephron. Z. Anat. Entwicklungsgesch 129:128-134.

21. Capasso, G., R. Kinne, G. Malnic, and G. Giebisch. 1986. Renal bicarbonate reabsorption in the rat. I. Effects of hypokalemia and carbonic anhydrase. $J$. Clin. Invest. 78:1558-1567.

22. Capasso, G., P. Jaeger, G. Giebisch, V. Guckian, and G. Malnic. 1987 Renal bicarbonate rebsorption in the rat. II. Distal tubule load dependence and effect of hypokalemia. J. Clin. Invest. 80:409-414.

23. Good, D. W. 1993. The thick ascending limb as a site of renal bicarbonate reabsorption. Semin. Nephrol. 13:225-235.

24. Kunau, R. T., Jr., J. I. Hart, and K. A. Walker. 1985. Effect of metabolic acidosis on proximal tubular total CO2 absorption. Am. J. Physiol. 249:F62-F68.

25. Cogan, M. G., and F. C. Rector. 1982. Proximal reabsorption during metabolic acidosis in the rat. Am. J. Physiol. 242:F499-F507.

26. Preisig, P. A., and R. J. Alpern. 1988. Chronic metabolic acidosis causes an adaptation in the apical membrane $\mathrm{Na} / \mathrm{H}$ antiporter and basolateral membrane $\mathrm{Na}(\mathrm{HCO} 3) 3$ symporter in the rat proximal convoluted tubule. J. Clin. Invest. 82:1445-1453.

27. Kinsella, J., T. Cujdik, and B. Sacktor. 1984. Na+- H+ exchange activity in renal brush border membrane vesicles in response to metabolic acidosis: the role of glucocorticoids. Proc. Natl. Acad. Sci. USA. 81:630-634.

28. Soleimani, M., G. L. Bizal, T. D. McKinney, and Y. J. Hattabaugh. 1992. Effect of in vitro metabolic acidosis on luminal $\mathrm{Na}+/ \mathrm{H}+$ exchange and basolateral $\mathrm{Na}+$ :HCO-3 cotransport in rabbit kidney proximal tubules. J. Clin. Invest. 90:211-218.

29. Khadouri, C., S. Marsy, C. Barlet-Bas, L. Cheval, and A. Doucet. 1992. Effect of metabolic acidosis and alkalosis on NEM-sensitive ATPase in rat nephron segments. Am. J. Physiol. 262:F583-F590.

30. Garg, L. C., and N. Narang. 1985. Stimulation of an N-ethylmaleimidesensitive ATPase in the collecting duct segments of the rat nephron by metabolic acidosis. Can. J. Physiol. Pharmacol. 63:1291-1296.

31. Krapf, R., D. Pearce, C. Lynch, X.-P. Xi, L. Reudelhuber, J. Pouysségur and F. C. Rector, Jr. 1991. Expression of rat renal $\mathrm{Na} / \mathrm{H}$ antiporter mRNA levels in response to respiratory and metabolic acidosis. J. Clin. Invest. 87:747-751.

32. Welbourne, T. C. 1976. Acidosis activation of the pituitary-adrenal-renal glutaminase I axis. Endocrinology. 99:1071-1079.

33. Perez, G. O., G. R. Oster, C. A. Vaamonde, and F. H. Katz. 1977. Effect of $\mathrm{NH} 4 \mathrm{Cl}$ on plasma aldosterone, cortisol, and renin activity in supine man. $J$. Clin. Endocrinol. Metab. 45:762-767.

34. Perez, G. O., J. R. Oster, F. H. Katz, and C. A. Vaamonde. 1979. The effect of acute metabolic acidosis on plasma cortisol, renin activity and aldosterone. Horm. Res. (Basel) 11:12-21.

35. Unwin, R., G. Capasso, S. Agulian, and G. Giebisch. 1990. Effect of adrenal steroids on loop of Henle bicarbonate transport. Kidney Int. 37:548.(Abstr.)

36. Oberleithner, H., M. Weight, H. J. Westphale, and W. Wang. 1987. Aldosterone activates $\mathrm{Na}+/ \mathrm{H}+$ exchange and raises cytoplasmic $\mathrm{pH}$ in target cells of the amphibian kidney. Proc. Natl. Acad. Sci. USA. 84:1464-1468.

37. Chan, Y. L., B. Biagi, and G. Giebisch. 1982. Control mechanisms of bicarbonate transport across the rat proximal convoluted tubule. Am. J. Physiol. 242:F532-F543.

38. Alpern, R. J. 1985. Mechanism of basolateral membrane $\mathrm{H}+/ \mathrm{OH}-/ \mathrm{HCO} 3$ transport in the rat proximal convoluted tubule. J. Gen. Physiol. 86:613-636.

39. Krapf, R. 1988. Basolateral membrane $\mathrm{H} / \mathrm{OH} / \mathrm{HCO} 3$ transport in the rat cortical thick ascending limb. J. Clin. Invest. 82:234-241.

40. Bastani, B., H. Purcell, P. Hemken, D. Trigg, and S. Gluck. 1991. Expression and distribution of renal vacuolar proton-translocating adenosine triphosphatase in response to chronic acid and alkali loads in the rat. J. Clin. Invest. 88:126136 .

41. Galla, J. H., D. N. Bonduris, and R. G. Luke. 1987. Effects of chloride and extracellular fluid volume on bicarbonate reabsorption along the nephron in metabolic alkalosis in the rat. J. Clin. Invest. 80:41-50.

42. Adam, W. R., A. P. Koretsky, and M. W. Weiner. 1986. 32P-NMR in vivo measurements of renal intracellular $\mathrm{pH}$ : effects of acidosis and $\mathrm{K}+$ depletion in rats. Am. J. Physiol. 251:F904-F910.

43. Adler, S., and D. S. Fraley. 1977. Potassium and intracellular pH. Kidney Int. 21:402-410.

44. Aronson, P. S., J. Nee, and M. A. Suhm. 1982. Modifier role of internal $\mathrm{H}+$ in activating the $\mathrm{Na}+-\mathrm{H}+$ exchanger in renal microvillus membrane vesicles. Nature (Lond.). 299:161-163.

45. Soleimani, M., J. A. Bergman, M. A. Hosford, and T. D. McKinney. 
1990. Potassium depletion increases luminal $\mathrm{Na}+-\mathrm{H}+$ exchange and basolateral $\mathrm{Na}+: \mathrm{CO} 3=: \mathrm{HCO}^{-}$cotransport in rat renal cortex. J. Clin. Invest. 86:1076-1083.

46. Cemerikic, D., C. S. Wilcox, and G. Giebisch. 1982. Intracellular potential and $\mathrm{K}+$ activity in rat kidney proximal tubular cells in acidosis and $\mathrm{K}+$ depletion. J. Membr. Biol. 69:159-165.

47. Liu, F.-Y., and M. G. Cogan. 1987. Acidification is inhibited in late proximal convoluted tubule during chronic metabolic alkalosis. Am. J. Physiol. 253:F89-F94.

48. Uhlich, E., C. A. Baldamus, and K. J. Ullrich. 1968. Verhalten von CO2Druck und Bicarbonat im Gegenstromsystem des Nierenmarks. Pflügers Arch. Eur. J. Physiol. 303:31-48.

49. Levine, D. Z., M. K. Byers, R. A. McLeod, and J. A. Luisello. 1979. Loop of Henle bicarbonate accumulation in vivo in the rat. J. Clin. Invest. 63:5966.

50. Capasso, G., F. Ciani, G. De Tommaso, M. Vinciguerra, R. Unwin, and N. G. De Santo. 1992. Luminal transport processes during in vivo acute metabolic alkalosis. Renal Physiol. Biochem. 15:173.(Abstr.)

51. Unwin, R., G. Capasso, T. Shirley, and R. Stidwell. 1993. Bicarbonate transport in the loop of Henle in acute and chronic respiratory acidosis and alkalosis. J. Am. Soc. Nephrol. 4:830.(Abstr.)

52. Stanton, B. A., and B. Kaissling: 1989. Regulation of renal ion transport and growth by sodium. Am. J. Physiol. 257:F1-F10.

53. Scherzer, P., H. Wald, and J. W. Czackes. 1985. Na-K-ATPase in isolated rabbit tubules after unilateral nephrectomy and $\mathrm{Na}+$ loading. Am. J. Physiol. 248:F565-F573.
54. Mujais, S. K., S. Kauffman, and A. I. Katz. 1986. Angiotensin II binding sites in individual segments of the rat nephron. J. Clin. Invest. 77:315-318.

55. Hall, J. E., and M. W. Brands. 1992. The Renin-Angiotensin-Aldosterone System. Renal mechanisms and circulatory homeostasis. In The Kidney: Physiology and Pathophysiology. D. W. Seldin and G. Giebisch, editors. Raven Press, Ltd., New York. 1455-1504.

56. Garvin, J. L. 1991. Angiotensin stimulates bicarbonate transport and $\mathrm{Na}+-$ K+ATPase in rat proximal straight tubules. J. Am. Soc. Nephrol. 1:1146-1152.

57. Terada, Y., K. Tomita, H. Nonoguchi, and F. Marumo. 1993. PCR localization of angiotensin II receptor and angiotensinogen mRNAs in rat kidney. Kidney Int. 43:1251-1259.

58. Kakinuma, Y., A. Fogo, T. Inagami, and I. Ichikawa. 1993. Intrarenal localization of angiotensin II type 1 receptor mRNA in the rat. Kidney Int. 43:1229-1235.

59. Geibel, J., G. Giebisch, and W. F. Boron. 1990. Angiotensin II stimulates both $\mathrm{Na}+-\mathrm{H}+$ exchange and $\mathrm{Na}+-\mathrm{HCO} 3-$ cotransport in the rabbit proximal tubule. Proc. Natl. Acad. Sci. USA. 87:7917-7920.

60. Bencsath, P., G. Szénasi, and L. Takacs. 1985. Water and electrolyte transport in Henle's loop and distal tubule after renal sympathectomy in the rat. Am. J. Physiol. 249:F308-F314.

61. DiBona, G. F., and L. L. Sawin. 1982. Effect of renal nerve stimulation on $\mathrm{NaCl}$ and $\mathrm{H}_{2} \mathrm{O}$ transport in Henle's loop of the rat. Am. J. Physiol. 243:F576F580.

62. Nord, E. P., M. J. Howard, A. Hafezi, P. Moradeshagi, S. Vaystub, and P. A. Insel. 1987. Alpha2 adrenergic agonists stimulate $\mathrm{Na}+-\mathrm{H}+$ antiport activity in the rabbit renal proximal tubule. J. Clin. Invest. 80:1755-1762. 